\title{
Substituent Effects on Thermal Decolorization Rates of Bisbenzospiropyrans
}

Nina T. Lu, Vi N. Nguyen, Satish Kumar, and Alison McCurdy ${ }^{*}$

The Department of Chemistry and Biochemistry, California State University, Los Angeles, 5151

State University Dr., Los Angeles, California 90032

\section{Abstract}
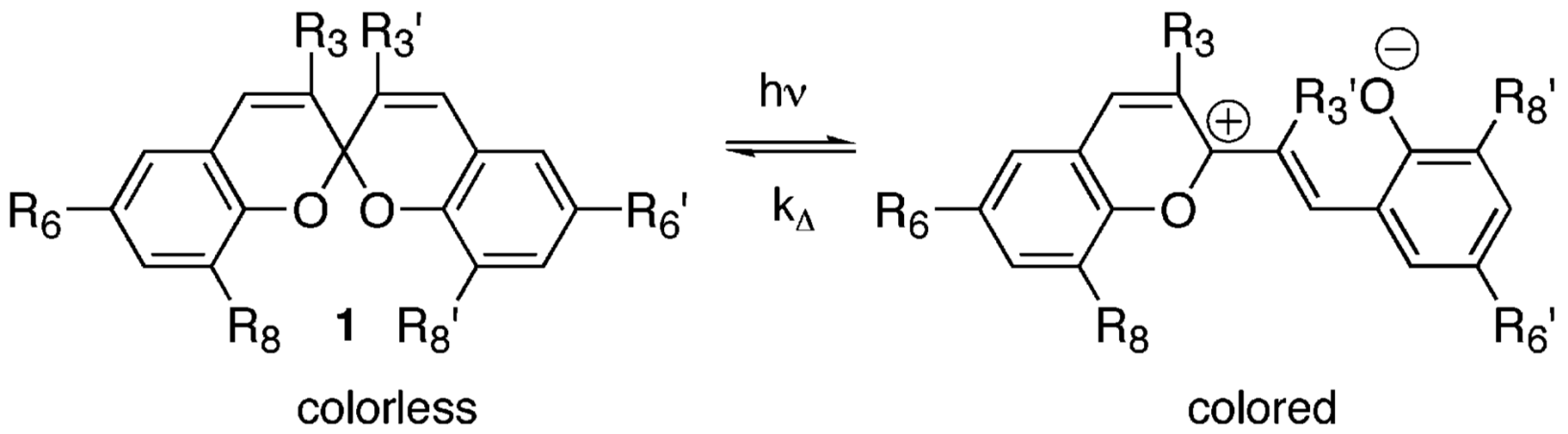

A novel application of photochromic molecules is to mimic physiological oscillatory calcium signals by reversibly binding and releasing calcium ions in response to light. Substituent changes on the largely unexplored photochromic bisbenzospiropyran scaffold led to significant changes in thermal fading rates in several organic solvents. Excellent correlations have been found between fading rates and empirical Hammett constants as well as calculated ground-state energies. These correlations can be used to improve scaffold design.

Calcium $\left(\mathrm{Ca}^{2+}\right)$ is a second messenger in important signal transduction systems that translate extracellular signals into cellular response. ${ }^{1}$ Often, in both excitable and nonexcitable cell types, the intracellular calcium signal is oscillatory. ${ }^{2}$ Extensive experimental and theoretical work has been carried out to understand how the oscillations arise, but much less is known about the effects of $\mathrm{Ca}^{2+}$ oscillations on a molecular level. Understanding calcium signaling will lead to insights about both normal and disease states in humans. Photoreversible calciumspecific chelators appear to be an effective approach to this area of research. Photochromic compounds are well suited for controlled ion binding and release because they undergo reversible structural changes upon irradiation that can form or disrupt a binding cavity. For reversible ion binding, the photochromic molecule must interconvert between low affinity (B) and high affinity (A) binding states. (Figure 1). The use of light to control metal ion binding and release is well documented. ${ }^{3-5}$ However, these systems lack specificity for calcium over other univalent and divalent cations, and are poorly soluble in water. To date, there are no calcium-selective binders that can be used to generate the wide spectrum of physiological oscillatory calcium signals in aqueous systems.

(C) 2005 American Chemical Society

*Address correspondence to this author. Phone: 323-343-2362. Fax: 323-343-6490, amccurd@ calstatela.edu. 
This novel application requires a compound with both suitable metal binding and appropriate photochemical properties. Compound 1, a substituted 2,2'-spirobi[2H-1-benzopyran] where $\mathrm{R}_{8,8^{\prime}}=-\mathrm{N}\left(\mathrm{CH}_{2} \mathrm{CO}_{2}^{-}\right)_{2}$ shown in Figure 2, was designed to serve as a photochromic calciumselective chelator. The shape of this photochromic scaffold uniquely allows multiple convergent chelating carboxylate ligands to be appended to it. The spiropyran class of photochromic compounds undergoes heterolytic cleavage from closed to open forms, and photochromism is observable at a given temperature unless the rate of thermal closure $\left(k_{\Delta}\right)$ is too fast. ${ }^{6,7}$ Prior work by this group on $\mathbf{1}\left(\mathrm{R}_{3,3^{\prime}}=-\mathrm{CH}_{3} ; \mathrm{R}_{8,8^{\prime}}=-\mathrm{N}\left(\mathrm{CH}_{2}-\mathrm{CO}_{2}{ }^{-}\right)_{2}\right)$ showed moderately strong and selective binding of calcium over magnesium in aqueous buffered systems, but was not found to be photochromic under our experimental conditions. ${ }^{8}$ Current efforts are directed toward a systematic investigation of the tunability of photochromic properties of bisbenzospiropyran, given the limited structure-activity data published for this photochromic scaffold. In this report, the effect of changing substituents on $k_{\Delta}$ is examined. These efforts will aid in assessing the viability of this photochromic scaffold for use in a calcium-signaling mimic.

The compounds listed in Table 1 were prepared according to literature methods ${ }^{9}$ as described in the Supporting Information.

Representative photochromic behavior is illustrated by Figure 3. After reaching a photostationary state upon UV irradiation at $-70{ }^{\circ} \mathrm{C}$, (thermal) fading was monitored in darkness at $-70^{\circ} \mathrm{C}$. This temperature was chosen so that kinetics of the fastest reaction monitored were slow relative to the instrument scan rate. Thermal fading follows first-order kinetics at shorter, but not at longer times. This complex kinetic behavior is also characteristic of many indolino-spiropyrans. ${ }^{7,10}$ Table 2 lists first-order rate constants analyzed at short times (first 10\% of experiment). As discussed in more detail below, these data show both solvent dependence and substituent effects on thermal fading rates. Qualitatively, the more polar solvent and the more electron donating substituent slow the rate of thermal fading. Higher temperatures increase the rate of thermal closure (data not shown) so that photocoloration is not observed at room temperature for these compounds.

The determination of $k_{\Delta}$ was not possible for certain compounds (1f- $l$ ). For example, substituents at $R_{3,3^{\prime}}$ prohibited photocoloration under these conditions. In contrast, prior work by Appriou et al. with a flashlamp showed related compounds substituted at $R_{3,3^{\prime}}$ were in fact photochromic at room temperature in toluene. ${ }^{11}$ The different intensity of the light sources may explain these different observations. Also, the presence of a nitro group (1f) caused an immediate change in the visible spectrum upon irradiation, suggesting very efficient photocoloration, but almost as quickly the signal disappeared, even while under irradiation. This is consistent with the observation that nitro groups improve quantum yields, but also can increase $k_{\Delta}$ and side reactions. ${ }^{12}$

More polar solvents lower the rate of thermal closure up to 100-fold (graphical representation of these data is in the Supporting Information). This effect is consistent with more polar solvents better stabilizing the more polar open form of the molecules. In addition, more polar solvents decrease the sensitivity of $k_{\Delta}$ to substituents. This trend has been observed for other photochromic spiropyrans, ${ }^{13}$ with a notable exception. One group has reported that substituent effects are negligible in nonpolar solvents, but strongly present in polar solvents. ${ }^{14}$ They cited a change in ground-state structure and mechanism due to solvation effects. In nonpolar solvents, a quinoid resonance form was dominant, following the substituent-insensitive electrocyclic ring closure pathway. In polar solvents, the zwitterionic resonance form was a major contributor, with large substituent effects on closure rates. The data in Table 2 do not suggest a mechanism change due to either substituent or solvent effects. 
The symmetric substitution of the bisbenzospiropyran decreases rates of thermal closure up to 20 -fold. These effects, while small, are significant. The same substituent at $\mathrm{R}_{6}$ and $\mathrm{R}_{6}{ }^{\prime}$ should have both stabilizing and destabilizing effects on the zwitterionic open form, which might be expected to cancel out completely. Interestingly, they do not.

Substituent effects have been studied on related spirobenzopyrans with indoline and benzothiazoline heterocyclic systems. ${ }^{7,11,15}$ In some cases, structural modifications have resulted in dramatic changes of thermal fading rate constants of 3-4 orders of magnitude in both nonpolar and polar solvents. Generally, as the open form is stabilized electronically by substituents, $k_{\Delta}$ decreases. A summary of specific substituent effects on $k_{\Delta}$ is illustrated with Figure 4 . Electron-donating substituents decrease $k_{\Delta}$ in positions $\mathrm{A}$ and $\mathrm{B}$, while electronwithdrawing substituents decrease $k_{\Delta}$ in position $\mathrm{C}$. These substituent effects were found to be additive. A dual parameter Hammett plot for kinetic data of a large number of indolinospirobenzopyrans yielded the following equation: $\log k)=(1.727) \times\left(\Sigma \sigma_{\text {indoline }}\right)-$ $(1.703) \times\left(\Sigma \sigma_{\text {pyran }}\right)-1.372(R=0.937){ }^{7}$

For purposes of comparison, an additive empirical Hammett-type plot of the form $a \times \sigma+b \times$ $\sigma+c$ was made here for bisbenzospiropyran. The slope $a$ should be positive for the electronpoor ring and the slope $b$ should be negative for the electron-rich ring. By using $\sigma_{\mathrm{p}+}$ and $\sigma_{\mathrm{p}-}$, an excellent correlation $(R=0.999)$ was obtained with the equation $\log k=(1.73) \times\left(\sigma_{\mathrm{p}+}\right)-$ $(0.653) \times\left(\sigma_{\mathrm{p}-}\right)-(0.914)$. Figure 5 shows predicted and observed values for each compound tested. Additional plots of predicted and observed $\log k_{\Delta}$ versus each independent variable $\left(\sigma_{\text {para+ }}\right.$ and $\left.\sigma_{\text {para- }}\right)$ are provided in the Supporting Information. A comparison of the slopes of the dual parameter Hammett plots reveals that the bisbenzospiropyran system studied here appears to have a larger difference in sensitivity to substituents between the two rings than the indolinospirobenzopyran system has. For 1a-e, the substituent effect on the electron-deficient ring is significantly more important than that for the electron-rich ring. This is consistent with the observation that even symmetric substitution influences $k_{\Delta}$. When substituents at $R_{8,8}$ are included (1m-o), the best fit requires the $E_{\mathrm{S}}$ (Taft) substituent parameter for position $\mathrm{R}_{8,8}$, and the overall fit decreases $(R=0.968)$. The best equation is $\log k=(2.155) \times\left(\sigma_{\mathrm{p}+}\right.$ or $\left.E_{\mathrm{S}}\right)-(1.452)$ $\times\left(\sigma_{\mathrm{p}-}\right.$ or $\left.E_{\mathrm{S}}\right)-(0.812)$.

A correlation between initial rates of thermal closure of 1a-e in methylcyclohexane and calculated quantities was also attempted. Density functional calculations (B3LYP/6-31G*) were performed to obtain ground-state energies of both closed spiro and open planar, conjugated forms (Table 3). Closed forms were found to be more stable than open forms by approximately $5-7 \mathrm{kcal} / \mathrm{mol}$. The open forms exist as eight possible stereoisomers. Each of the three bonds of the chain linking the aromatic rings may be cisoid ("c") or transoid ("t"). For compounds 1a-e, the lowest energy open stereoisomer is "ctc", shown in Figure 2. Illustrations of all eight stereoisomers including stereochemical designations are included in the Supporting Information.

Unlike other reports, ${ }^{15 b, c}$ no correlation was found here between $\log k_{\Delta}$ and any calculated bond length, bond length alternation in the open form, HOMO-LUMO gap of closed or open forms, or dipole change. However, there was excellent correlation between $\left(E_{\text {clsosed }}-E_{\text {open }}\right)$ and $\log k_{\Delta}(R=0.996-0.953$ for the four most stable transoid isomers of each compound). These plots are included in the Supporting Information. As substituents stabilize the open form relative to the less polar transition state, the kinetic barrier to thermal closure increases.

This work demonstrates that both solvent and substituents can be used to tune the photochromism of 2,2'-spirobi[1H-1-benzopyran]. To mimic biological calcium signals at physiological temperatures, the original designed chelator 1 where $\mathrm{R}_{3,3^{\prime}}=\mathrm{CH}_{3} ; \mathrm{R}_{6,6^{\prime}}=\mathrm{H}$; $\mathrm{R}_{8,8^{\prime}}=\mathrm{N}\left(\mathrm{CH}_{2} \mathrm{CO}_{2}\right)_{2}$ must be modified significantly. The present study also demonstrates that 
the synthetically simple symmetric substitutions used here are not sufficient. However, we have shown that either computational or empirical Hammett correlations can be used reliably to design a more appropriate scaffold. For example, the Hammett equation predicts that if $\mathrm{R}_{6}$ $=\mathrm{NMe}_{2}$ and $\mathrm{R}_{6^{\prime}}=\mathrm{CN}$, the molecule's thermal closure rates will be approximately 500 -fold slower than the slowest rate reported here. If water solvation does not overwhelm substituent effects and if photocoloration remains efficient, these new scaffolds should allow the observation of photochromism under physiological conditions. The optimized photochromic chelator will be used to gain insight into complex calcium signaling on a molecular level.

\section{Experimental Section}

\section{Photochemistry}

Light from a 200-W Mercury Xenon lamp, filtered by water and a $320 \mathrm{~nm}$ band-pass filter, was directed via a 3 -ft quartz fiber optic bundle into the top of a reaction vessel. The irradiated, stirred samples were cooled, using a thermostated cryobath, to various temperatures. UV-vis observations were made with a Hellma 10-mm immersion probe.

\section{Computation}

The program Spartan ' 04 was used. Closed forms were subjected to geometry optimization (B3LYP/6-31G*) and the resulting geometry was used to determine energy. For open forms, two isomers ("ttt" and "tcc") were used as starting points to generate a conformer distribution (four isomers in each distribution). A figure defining the structures of the open forms is included in the Supporting Information. For compounds with methoxy substituents, AM1 was used to generate the conformer distribution. The conformers were subjected to geometry opimization (B3LYP/6-31G*) and then single point energy determination. Cartesian coordinates and energies are listed after synthetic and spectral data of the Supporting Information.

\section{6,6'-Dimethoxy-2,2'-spirobi[2H-1-benzopyran] (1a)}

The following are representative procedures for syntheses of the molecules studied here.

\section{Base-catalyzed route}

5-Methoxysalicyladehyde (1.22 g, $8.02 \mathrm{mmol})$, acetone ( $0.3 \mathrm{~mL}, 4.04 \mathrm{mmol}), 4 \mathrm{~N} \mathrm{NaOH}(4$ $\mathrm{mL}, 16 \mathrm{mmol})$, and ethanol $(5 \mathrm{~mL})$ were stirred in a $25-\mathrm{mL}$ round-bottom flask at room temperature for $12 \mathrm{~h}$. The resulting reaction mixture was added to water and neutralized with $5 \% \mathrm{HCl}(25 \mathrm{~mL})$. The precipitate was extracted into ethyl acetate, which was dried over anhydrous $\mathrm{MgSO}_{4}$ and evaporated under reduced pressure. The residue was dried under vacuum and added to ethoxyethyl acetate $(10 \mathrm{~mL})$ in a $25-\mathrm{mL}$ round-bottom flask. The resulting solution was refluxed for $1 \mathrm{~h}$. The reaction was monitored by TLC, which indicated completion of reaction after $1 \mathrm{~h}$. The reaction mixture was cooled and poured in water and extracted into diethyl ether. The organic layer was washed twice with $1 \mathrm{M} \mathrm{NaOH}$. The organic layer was dried over $\mathrm{MgSO}_{4}$ and evaporated under reduced pressure. The resulting crude product was subjected to flash column chromatography on silica gel. The product was eluted with $15 \%$ diethyl ether in hexane. Yield $17.10 \%$.

\section{Acid-catalyzed route}

5-Methoxysalicyladehyde $(0.5 \mathrm{~mL}, 4.0 \mathrm{mmol})$, acetone $(0.30 \mathrm{~mL}, 4.04 \mathrm{mmol})$, and a stir bar were added to a round-bottom flask containing anhydrous ethanol $(10 \mathrm{~mL})$. The reaction mixture was cooled with the help of an ice bath and hydrochloric acid gas was bubbled through the reaction for $2 \mathrm{~h}$. The reaction mixture was allowed to come to room temperature and stirred for $24 \mathrm{~h}$. After $24 \mathrm{~h}, 5$-methoxysalicyladehyde $(0.5 \mathrm{~mL}, 4.0 \mathrm{mmol})$ was added to the reaction mixture, cooled with an ice bath, and $\mathrm{HCl}(\mathrm{g})$ was bubbled through the reaction for another 2 
h. The following day, the reaction was extracted with methylene chloride several times. The organic layer was dried over $\mathrm{MgSO}_{4}$. The crude material was subjected to flash column chromatography on silica gel. The product was eluted with $10 \%$ ethyl acetate in hexane. Yield $31 \%$.

${ }^{1} \mathrm{H}$ NMR (300 MHz, $\left.\mathrm{CDCl}_{3}\right): \delta 6.83-6.75(\mathrm{~m}, 8 \mathrm{H}), 6.01-5.98(\mathrm{~d}, J=9 \mathrm{~Hz}, 2 \mathrm{H}), 3.79(\mathrm{~s}$, $6 \mathrm{H}) .{ }^{13} \mathrm{C}$ NMR $\left(75 \mathrm{MHz}, \mathrm{CDCl}_{3}\right): \delta 154.6,145.0,126.8,122.6,120.4,117.6,115.9,111.9$, 95.3, 56.0. HRMS (DEI) $(\mathrm{m} / \mathrm{z})$ : calcd $\mathrm{M}^{+}$308.1150; found $308.1043\left(\mathrm{M}^{+}\right)$.

\section{Supplementary Material}

Refer to Web version on PubMed Central for supplementary material.

\section{Acknowledgment}

This work was supported by a generous grant from the National Institutes of Health (NIGMS MBRS S06 GM08101).

\section{References}

(1). (a) Berridge MJ, Cobbold PH, Cuthbertson KSR. Philos. Trans. R. Soc. London, Ser. B 1988;320:325-343. [PubMed: 2906142]Carafoli, E.; Klee, C., editors. Calcium as a Cellular Regulator. Oxford University Press; New York: 1999. (c) Clapham DE. Cell 1995;80:259-268. [PubMed: 7834745]

(2). Bootman MD, Lipp P, Berridge MJ. J. Cell Sci 2001;114:2213-2222. [PubMed: 11493661]

(3). Winkler, JD. Biological Applications of Photochemical Switches. Morrison, H., editor. John Wiley and Sons; New York: 1993. Chapter 3

(4). (a) Kimura K. Coord. Chem. Rev 1996;148:41-61. (b) Desvergne J-P, Bouas-Laurent H, PerezInestrosa E, Marsau P, Cotrait M. Coord. Chem. Rev 1999;185-186:357-371. (c) Tanaka M, Kamada K, Ando H, Kitagaki T, Shibutani Y, Kimura K. J. Org. Chem 2000;65:4342-4347. [PubMed: 10891136] (d) Itagaki H, Masuda W, Hirayanagi Y. Chem. Phys. Lett 1999;309:402406. (e) Takeshita M, Irie M. J. Org. Chem 1998;63:6643-6649. (f) Stauffer MT, Knowles DB, Brennan C, Funderburk L, Lin F-T, Weber SG. Chem. Commun 1997:287-288.

(5). (a) Filley J, Ibrahim MA, Nimlos MR, Watt AS, Blake DM. J. Photochem. Photobiol. A 1998;117:193-198. (b) Collins GE, Choi L-S, Ewing KJ, Michelet V, Bowen C, Winkler JD. Chem. Commun 1999:321-322. (c) Stauffer MT, Weber SG. Anal. Chem 1999;71:1146-1151. (d) Wojtyk JTC, Kazmaier PM, Buncel E. Chem. Commun 1998:1703-1704.

(6). Minkin VI. Chem. Rev 2004;104:2751-2776. [PubMed: 15137806]

(7). Bertelson, RC. Photochromism. Brown, GH., editor. Vol. III. Wiley-Interscience; New York: 1971. p. 45-431.Techniques of Chemistry

(8). McCurdy A, Kawaoka AM, Thai H, Yoon S. Tetrahedron Lett 2001;42:7763-7766.

(9). (a) Bergmann ED, Weizmann A, Fischer E. J. Am. Chem. Soc 1950;72:5009-5012. (b) Inbasekaran M. Heterocycles 1993;35:1121-1123.

(10). Delbaere S, Micheau J, Vermeersch G. J. Org. Chem 2003;68:8968-8973. [PubMed: 14604369]

(11). Appriou P, Trebaul C, Brelivet J, Garnier F, Guglielmetti R. Bull. Soc. Chim. Fr 1976:2039-2045.

(12). Malatesta, V. Organic Photochromic and Thermochromic Compounds. Crano, JC.; Guglielmetti, RJ., editors. Vol. 2. Plenum Press; New York: 1999. Chapter 2

(13). (a) Samat A, Metzger J, Mentienne F, Garnier F, Duboius JE, Guglielmetti R. J. Phys. Chem 1972;76:3554-3558. (b) Vandewyer PH, Hoefnagels JH, Smets G. Tetrahedron 1969;25:32513266. (c) Keum S, Hur M, Kazmaier PM, Buncel E. Can. J. Chem 1991;69:1940-1947. (d) Wojtyk JTC, Wasey A, Kazmaier PM, Hoz S, Buncel E. J. Phys. Chem. A 2000;104:9046-9055.

(14). Keum S, Lee K. Bull. Korean Chem. Soc 1993;14:16-18.

(15). Bertelson, RC. Organic Photochromic and Thermochromic Compounds. Crano, JC.; Guglielmetti, RJ., editors. Vol. 1. Plenum Press; New York: 1999. Chapter 1 (b) Sheng Y, Leszczynski J, Garcia 
A, Rosario R, Gust D, Springer J. J. Phys. Chem. B 2004;108:16235-16243. (c) Kawanishi Y, Seki K, Tamaki T, Sakuragi M, Suzuki Y. J. Photochem. Photobiol. A 1997;109:237-242. 


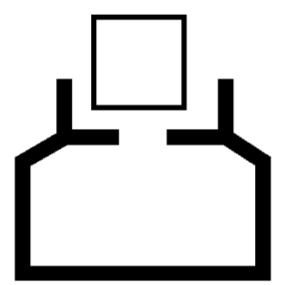

A

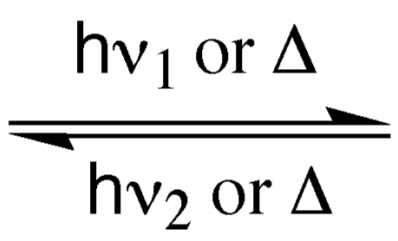

B

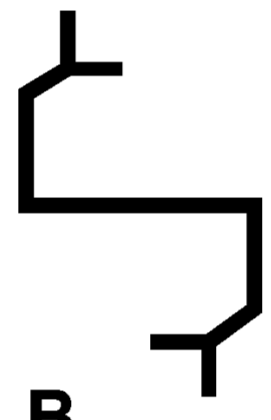

Figure 1.

Representation of a photochromic chelator. The square represents a metal ion. 

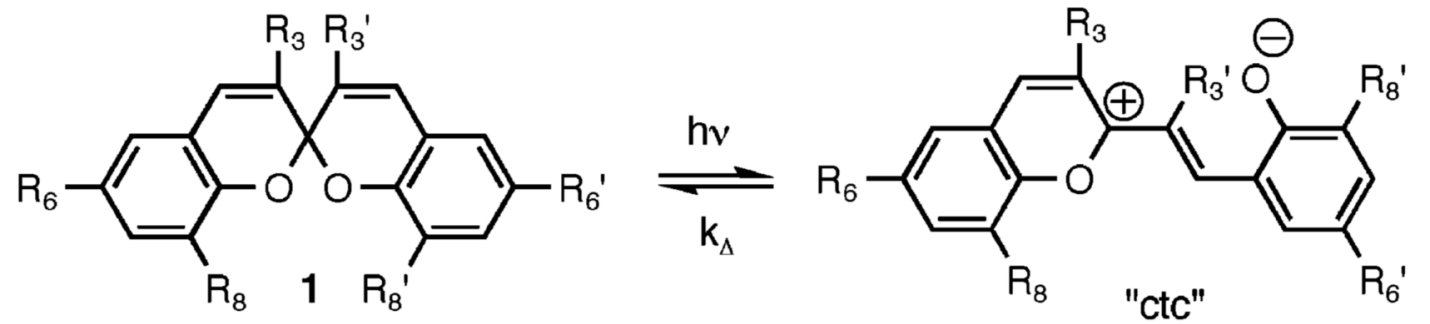

Figure 2.

Photochromic scaffold bisbenzospiropyran $\mathbf{1}$ as well as one of eight possible stereoisomeric open forms. 

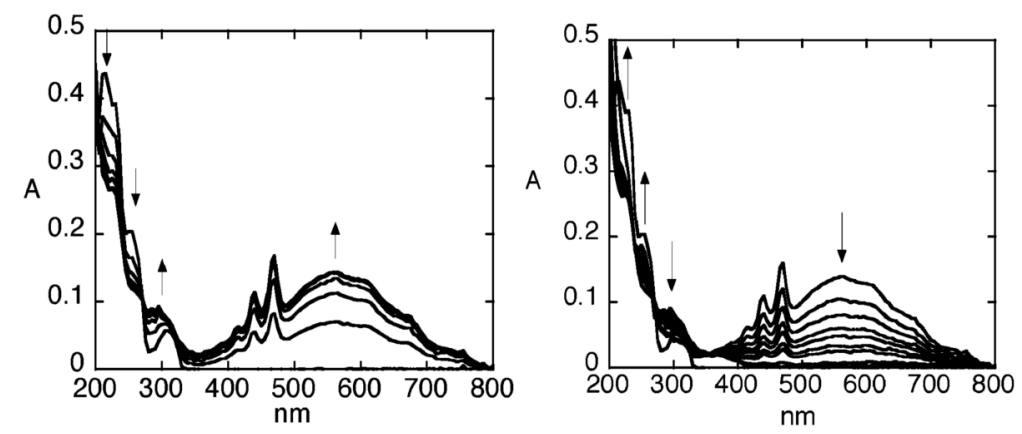

Figure 3.

UV-vis spectra showing the photochemical opening of $\mathbf{1 b}$ in methylcyclohexane at $-70{ }^{\circ} \mathrm{C}$ with UV light (left, during 6 min of irradiation) and thermal fading (right, during $200 \mathrm{~min}$ of darkness). 

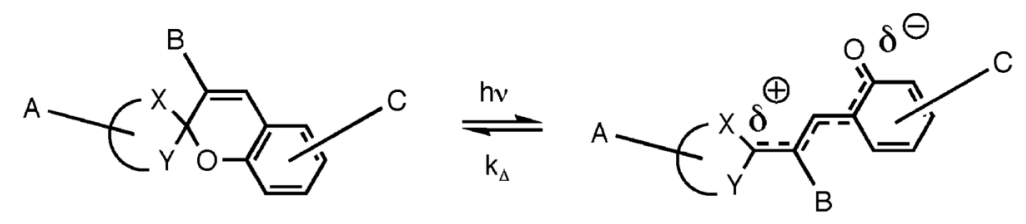

Figure 4.

Substituent effects in positions $\mathrm{A}, \mathrm{B}$, and $\mathrm{C}$ on $k_{\Delta}$. The heterocyclic ring is indoline or benzothiazoline. 


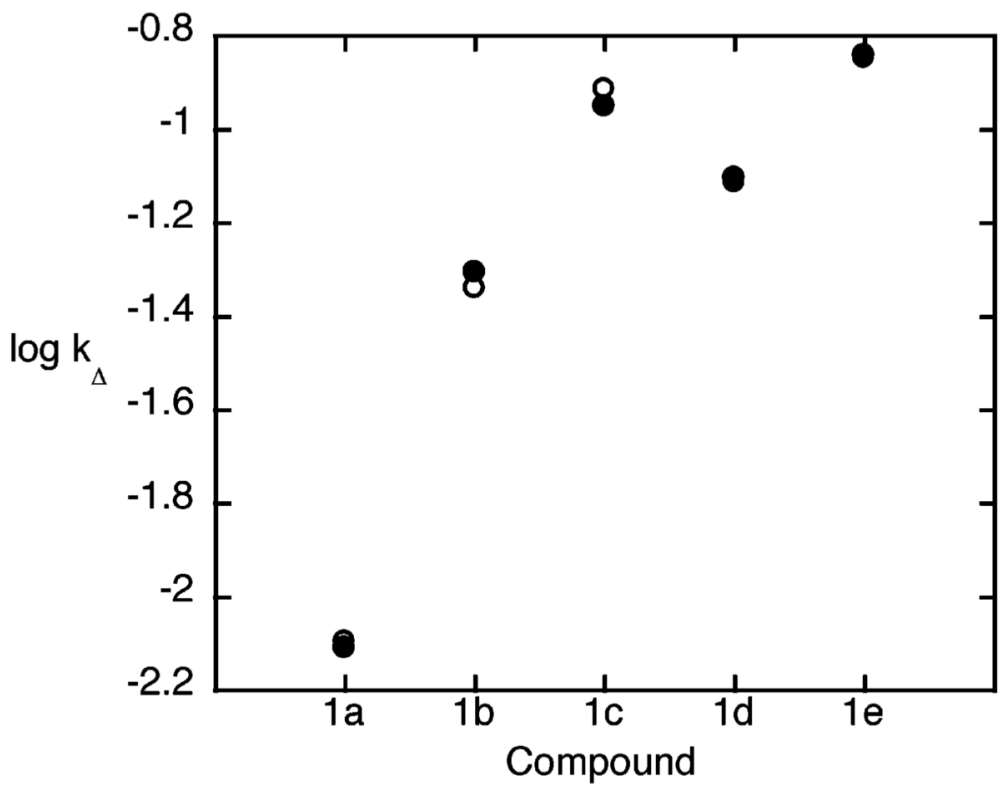

Figure 5.

For compounds 1a-e, experimental $\log k_{\Delta}$ (closed circles) compared to predicted values (open circles) obtained from a dual parameter Hammett plot (multiple $R=0.999$ when $\sigma_{\mathrm{p}+}$ and $\sigma_{\mathrm{p}-}$ parameters were used). 


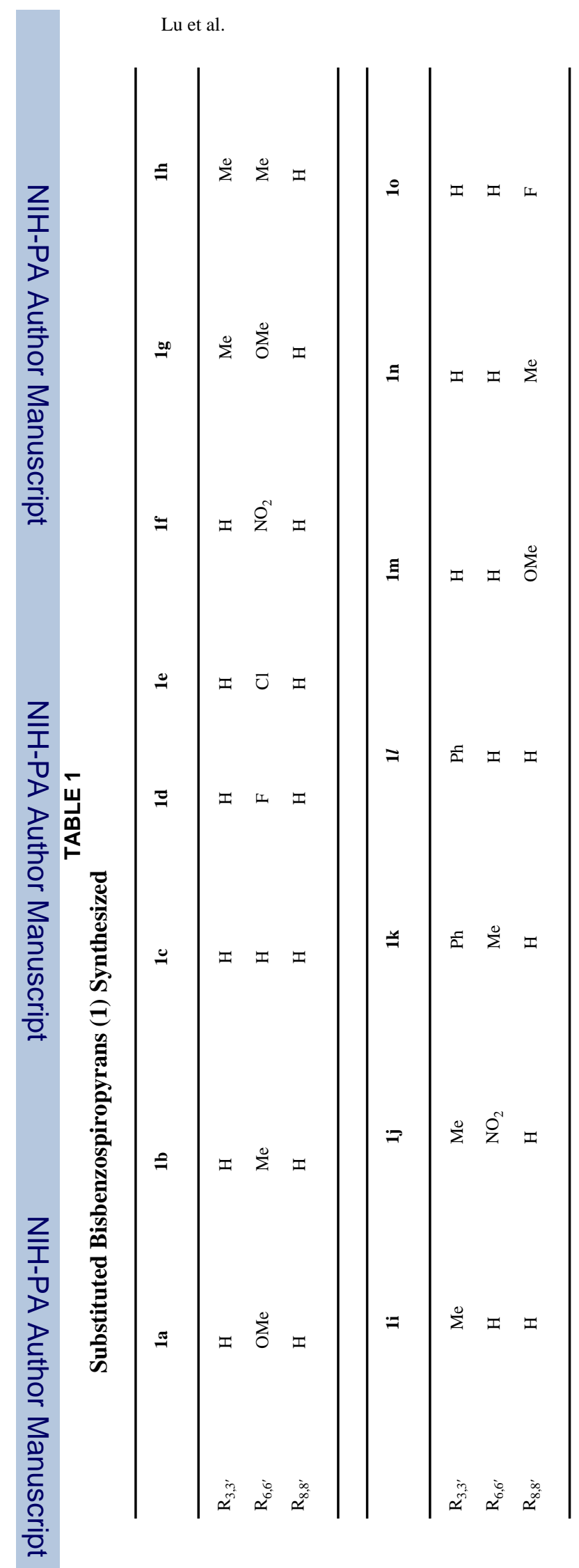

Page 12 
TABLE 2

Thermal Fade Rate Constants at $-\mathbf{7 0}{ }^{\circ} \mathrm{C}$ for Selected Compounds 1 in Various Solvents

\begin{tabular}{lllll}
\hline & \multicolumn{3}{c}{$\boldsymbol{k}_{\mathbf{\Delta}}\left(\mathbf{m i n}^{-\mathbf{1}}\right)$} \\
\cline { 2 - 5 } & $\mathbf{M e C y}$ & toluene & THF & ${ }^{i} \mathbf{P r O H}$ \\
\hline $\mathbf{6 - O M e}$ & $7.75 \times 10^{-3}$ & $4.20 \times 10^{-3}$ & $2.19 \times 10^{-3}$ & $1.65 \times 10^{-3}$ \\
$\mathbf{6 - M e}$ & $4.94 \times 10^{-2}$ & $1.37 \times 10^{-2}$ & $8.77 \times 10^{-3}$ & $2.09 \times 10^{-3}$ \\
$\mathbf{6 - H}$ & $1.12 \times 10^{-1}$ & $1.32 \times 10^{-2}$ & $1.09 \times 10^{-2}$ & $1.50 \times 10^{-3}$ \\
$\mathbf{6 - F}$ & $7.86 \times 10^{-2}$ & $1.64 \times 10^{-2}$ & $8.91 \times 10^{-3}$ & $2.65 \times 10^{-3}$ \\
$\mathbf{6 - C l}$ & $1.44 \times 10^{-1}$ & $1.61 \times 10^{-2}$ & $8.52 \times 10^{-3}$ & $7.24 \times 10^{-3}$ \\
$\mathbf{1 f - l}$ & $\mathrm{N} / \mathrm{A}$ & & & \\
$\mathbf{8}-\mathbf{O M e}$ & $8.32 \times 10^{-2}$ & & & \\
$\mathbf{8 - M e}$ & $1.88 \times 10^{-2}$ & & & \\
$\mathbf{8 - F}$ & $9.27 \times 10^{-2}$ & & & \\
\hline
\end{tabular}




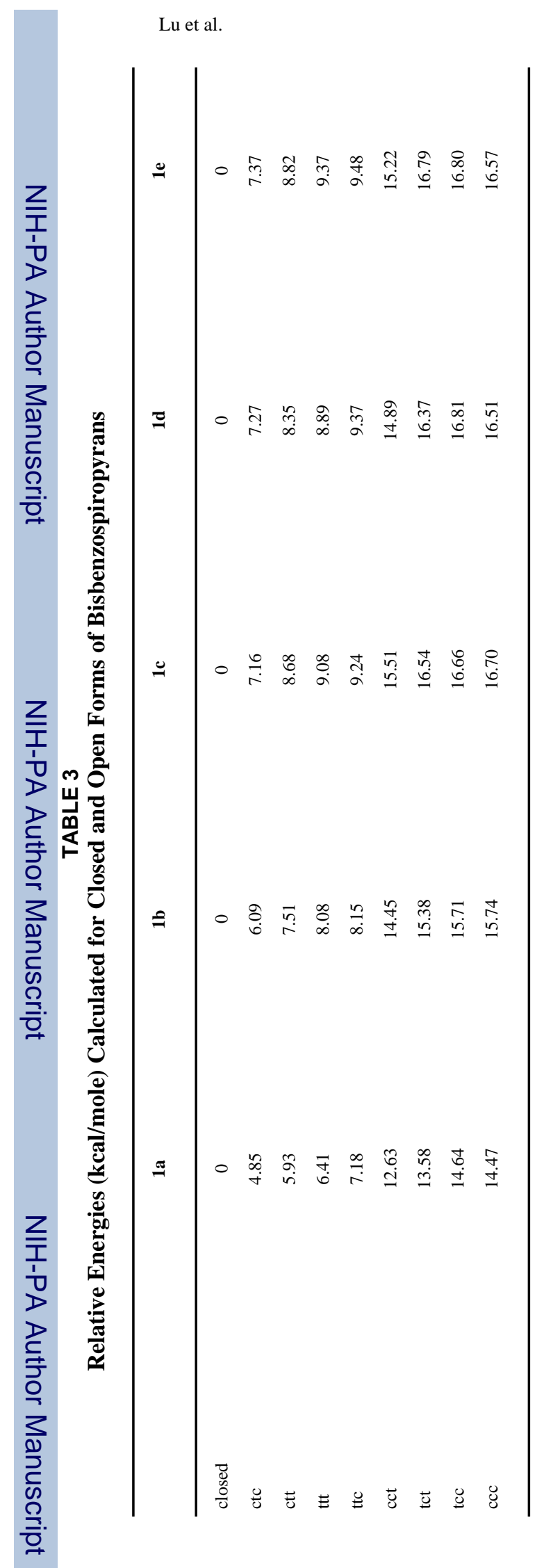

Page 14 